\title{
FUNGSI PERIBAHASA BANYUMAS
}

Oleh

\author{
M. Riyanton \\ Dosen Fakultas Ilmu Budaya Pendidikan Bahasa Indonesia Kampus Unsoed \\ Karangwangkal Jl. Dr. Soeparno Telp. (0281) 625152-Purwokerto 53123 \\ muhammadriyanton@gmail.com
}

\begin{abstract}
ABSTRAK
Penelitian ini bertujuan untuk mendeskripsikan dan menganalisis fungsi penggunaan peribahasa bahasa Jawa Banyumas. Penelitian ini merupakan penelitian kualitatif deskriptif dengan pendekatan etnolinguistik. Dalam penelitian ini informasi dideskripsikan secara teliti dan analisis. Strategi penelitian yang digunakan adalah studi kasus tunggal yang dilakukan pada satu karakteristik dan satu sasaran (subjek), yaitu peribahasa di Kabupaten Banyumas. Data penelitian dikumpulkan melalui beberapa sumber yaitu, informan, dan dokumen.Teknik pengumpulan data yang digunakan meliputi observasi partisipatori langsung,wawancara, dan analisis dokumen.Teknik cuplikan yang digunakan adalah purposive sampling. Hasil penelitian bahwa fungsi peribahasa Banyumas adalah fungsi budaya; fungsi bahasa; fungsi etika; fungsi sosial; fungsi ekonomi; fungsi; dan fungsi geografis.
\end{abstract}

Kata Kunci: Fungsi Peribahasa dan Kearifan Lokal

\section{ABSTRACT}

This study aims to describe and analyze the use of Banyumas Javanese proverbs. This research is a descriptive qualitative research with ethnolinguistic approach. In this research the information is described thoroughly and analysis. The research strategy used is single case study conducted on one characteristic and one target (subject), that is proverb in Banyumas regency. Research data was collected through several sources, ie informants, and documents. Data collection techniques used include direct participatory observation, interviews, and document analysis. The sampling technique used is purposive sampling. The result of research that the function of Banyumas proverb is cultural function; language function; ethical functions; social functions; economic functions; function; and geographical functions.

Keywords: Function of Proverbs and Local Wisdom

\section{PENDAHULUAN}

Indonesiamerupakannegara yang begitu kaya dengan khasanah kebudayaannya karena memiliki banyak etnis atau suku bangsa. Setiap budaya memiliki kekhasannya masing-masing dan mencerminkan nilai-nilai kehidupan yang berbeda. Oleh karenanya merupakan hal yang biasa ketika berbicara tentang suatu komunitas atau etnis tertentu, pertanyaan yang pertamakali muncul adalah bagaimana adat istiadat mereka, gaya hidup mereka, cara mereka berkomunikasi, dan lain sebagainya. Penelitian ini bertujuan untuk mengkaji ranah budaya dan bahasa, khususnya dalam bahasa dan budaya masyarakat biasanya terkandung kearifan lokal berupa perangkat pengetahuan dan praktik-praktik yang dapat digunakan untuk menyelesaikan persoalan dengan cara yang baik dan benar.

Budaya mengacu pada seperangkat praktik, kode, dan nilai yang menandai suatu kelompok. Membahas budaya memang tidak akan terlepas dari cara dan media komunikasi tidak terlepas dari posisi bahasa sebagai sebuah media ekspresi dari cermin 
pikiran manusia. Jadi, bahasa merupakan wadah dan refleksi suatu budaya. Melalui bahasa, manusia dapat menyesuaikan diri dengan adatistiadat, tingkah laku,tata karma masyarakat, dan sekaligus mudah membaur kandirinya dengan segala bentuk masyarakat.

Peribahasa J a wa B a n yu mas merupakan salah satu bentuk gaya bahasa yang berupa ungkapan tradisional atau suatu kiasan bahasa yang berupa kalimat atau kelompok kata yang bersifat padat, ringkas, sederhana dan berisi tentang norma,nilai, nasihat, perbandingan, perumpamaan, prinsip dan aturan tingkah laku. Dalam budaya masyarakat Jawa, Banyumas peribahasa banyak digunakan untuk menyampaikan pesan-pesan atau nilai-nilai kearifan lokal tertentu. Bahasa Jawa merujuk pada definisi kearifan lokal sebagai perangkat pengetahuan dan praktik-praktik yang dapat digunakan untuk menyelesaikan persoalanyang dihadapidengancarabaikdanbenar (Ahimsa 2007: 32).

Berdasarkan latar belakang di atas, penelitian etnografi dalam bidang pemahaman budaya yang tercermin dalam peribahasa sangat penting dilakukan dalam kaitannya dengan pemahaman kepribadian dan nilai- nilai budaya lokal. Suku bangsa yang memiliki kekhasan peribahasa yang sarat keragaman ini memerlukan pemahaman yang lebih dalam, khususnya untuk memahami maksud, makna, dan nilai- nilai yang terkandung didalamnya. Ruang lingkup penelitian ini adalah peribahasa yang terdapat serta digunakan dalam bahasa Jawa Banyumas, mengidentifikasi fungsi- fungsi penggunaan peribahasa bahasa Jawa Banyumas.

\section{METODE PENELITIAN}

Penelitian ini merupakan penelitian kualitatif yang bersifat deskriptif. Metode deskriptif digunakan untuk mendeskripsikan kearifan lokal peribahasa Banyumas. Sumberdatautamadalampenelitiankualitatifadalah kata- kata, tindakan selebihnya adalah data tambahan seperti dokumen dan lain- lain (Moleong, 1993: 112). Populasi dalam penelitian ini adalah masyarakat di Kabupaten Banyumas, sedangkan sampel adalah sebagian dari populasi yang mewakili dijadikan objek penelitian langsung (Subroto, 1992:36). Penelitian ini bersifat deskriptif kualitatif dengan memanfaatkan metode etnografi dengan model analisis etnosains (Spradley, 1997: 19). Sumber data dan data penelitian meliputi primer dan sekunder berupa ekspresi verbal (peribahasa Banyumas) dan nonverbal (konteks, peristiwa budaya) yang mengadung kearifan lokal dalam konteks bahasa dan budaya Jawa masyarakat di Kabupaten Banyumas dengan teknik purposive sampling, di samping itu menggunakan snow-ball sampling, proses ini berkelanjutan hingga mendapatkan data yang lengkap (Sutopo, 2006: 45-46). Teknik pengumpulan data dengan (1) participant observation(Spradley, 1997: 106) dan (2) in-depht-interviewing dengan informan terpilih untuk menafsirkan peribahasa Jawa masyarakat di Kabupaten Banyumas.Analisis dengan model etnosains, terutama analisis taksonomi, komponensial, dan domain yang relevan dengan analisis berdasarkan tema-tema budaya (Spradley, 1997: 120). Validitas data ditempuh dengan teknik triangulasi (triangulation), review informan kunci (key informant 
review) dan member check (Sutopo, 2006: 92).

\section{HASIL DAN PEMBAHASAN}

Peribahasadidefinisikan sebagaikalimat atau penggalan kalimat yang telah membeku bentuk, makna, dan fungsinya dalam masyarakat;bersifat turun temurun; dipergunakan untuk penghias karangan atau percakapan, penguat maksud karangan,pemberi nasihat, pengajaran atau pedoman hidup;mencakup bidal, pepatah, perumpamaan,ibarat dan pemeo (Harimurti Kridalaksana, 2001: 169). Dalam penelitian ini menelaah tentang fungsi peribahasa yang ada di Banyumas, adapun hasilnya sebagai berikut.

\section{Fungsi Budaya}

Budaya adalah daya dan budi yang berupacipta, karsa, dan rasa. Sedangkan kebudayaan adalah hasil dari cipta, karsa, dan rasaitu. Dalam istilah antropologi- budaya tidak ada perbedaan. Kata "budaya" di sini hanya dipakai sebagai suatu singkatan saja dari "kebudayaan” dengan arti yang sama (Koenjaraningrat, 2009:146).

Fungsi budaya memiliki eksistensi pemakaian peribahasa Banyumas yang mengandung kearifan lokalantara lain karena adanya tuntutan tradisi turun temurun yang telah berjalan antar generasi. Secara kultural masyarakat di Kabupaten Banyumas menjadi bagian dari budaya Jawa yang mempunyai kearifan lokal yang berbeda.Terekspresikan dengan istilah memetri „,mencermati, menyusun, memperhatikan, memelihara dan nguriuri "memelihara, mempertahankan"e bahasa dan budaya Banyumas yang mengandung kearifan lokal agar dapat didengar, ditulis, ditiru, dipakai, dipedomani nilai positifnya untuk menghindari nilai negatifnya. Maka dari itu, tidak mengherankan apabila para leluhur bahasa dan budaya Banyumasan memanfaatkan kesempatan yang ada untuk mengekspresikan peribahasa Banyumas yang mengandung kearifan lokal. Hal itu dilakukan agar pesan yang terkandung di dalamnya menjadi bermanfaat untuk menjalani hidup dan kehidupannya, sehingga mereka bisa mengikuti naluri positif kebanyumasannya.Oleh karena itu, perilaku seperti itu dapat diidentifikasi sebagai ekspresi kearifan lokal dalam budayanya.

Peribahasa fungsi budaya antara lain(a) Ngukur amben. Dalam bahasa Indonesia ngukur berarti "mengukur" dan amben berarti "tempat tidur". Jadi ngukur amben merupakan peribahasa untuk orang yang sedang tidur, karena orang tidur seolah-olah sedang mengukur tempat tidur dengan menggunakan tubuhnya sendiri. Contoh kalimat menggunakan peribahasa ngukur amben, "Bocah Puasa koh gawene ngukur amben mbok ya dolan apa ngaji ben seger" (Orang berpuasa kok kerjanya tidur saja, lebih baik bermain atau pergi mengaji supaya lebih segar ).(b) Kembang bale.Kembang dalam bahasa Indonesia berarti "bunga" dan bale berarti "ruang tamu". Kembang bale merupakan sebutan bagi orang yang kesehariaannya hanya duduk-duduk dan bersantai di ruang tamu. Contoh kalimat menggunakan peribahasa kembang bale,"Pak, mbok ya nggolet gawean, 
aja mung dadi kembang bale kaya kuwe" (Pak lebih baik mencari kerjaan, dari pada bersantai-santai seperti itu).(c) Enyong Langka Rika Ora Rame. Artinya : Enyong adalah sebutan "aku", sedangkan "rika" adalah sebutan "kamu". Masyarakat Banyumas terbiasa untuk hidup rukun, hidup sebagai mahluk sosial, tidak senang untuk hidup sebagai mahluk yang individualis. Jadi, kita akan merasa kurang apabila tidak melakukan sesuatu secara bersama-sama. Ibaratnya "aku" tidak bisa melakukan sesuatu sendiri tanpa "kamu”.Jadi, kita harus selalu bersama.Untuk memupuk rasa persaudaraan dan kekeluargaan, hubungan antar warga untuk menunjang semangat gotong-royong juga merupakan prinsip dalam pola kekerabatan yang dilakukan oleh masyarakat Banyumas. Wujud dari semangat gotong royong merupakan konsep kerja sama yang dijunjung tinggi, hal ini sangat akrab dengan kehidupan masyarakat petani-agraris.Masyarakat di Banyumas dalam kelangsungan hidupnya selalu mengutamakan kerukunan dan kebersamaan.Pada prinsipnya kekeluargaan dan gotong-royong dikedepankan, semua beban ditanggung bersama antar warga masyarakat.Prinsip demikian masih dipegang teguh yang merupakan rangkaian kehidupan yang saling tolong-menolong dengan sesama warga dan keluarga.

\section{Fungsi Bahasa}

\section{a. Peribahasa dan Ungkapan Jawa Berleksikon Tumbuhan}

(1) Aja ngarepna endoge bosok. Artinya jangan mengharapkan ketidakpastian.Maksudnya, janganlah berangan-angan mengharapkan sesuatu yang belum pasti, diibaratkan endoge blorok (telurnya ayam blorok), ayam belum tentu bertelur tetapi sudah diharapkan telurnya. (2) Aji godong garing. Artinya adalah jelek sekali perilakunya, atau tidak ada nilainya sama sekali. (3) Ngewaneni endas, artinya orang yang berani melawan raja atau pemerintah. (4) Debog bosok, artinya orang yang sudah buruk rupa, perangainya juga jahat. (5) Nggered pring sing pucuk, artinya gaweyan kang gampang, ndadak digawe angel (mengurai suatu masalah bukan dari pangkalnya, sehingga membuat masalah semakin rumit dan sulit terselesaikan).(5) Asem sing gunung, uyah sing laut dadi siji nang kuwali.Artinya, artinya Laki-laki dan perempuan kalau sudah jodoh pasti akan bertemu juga. (6) Esuk dele sore tempe. Artinya, artinya padi kedelai, sore tempe. Sindiran terhadap orang yang suka mencla-mencle, tak menepati janji.Perkataannya selalu berubah-ubah, sekarang berkata begini, sebentar lagi bilang begitu.Akibat sifat perilakunya itu yang bersangkutan sulit memperoleh kepercayaan orang (masyarakat). (7) Gajah kalingan suket teki, artinya orang yang berpura-pura (ucapan dan hatinya tidak sama), akhirnya ketahuan juga maksudnya.

\section{b. Peribahasa dan Ungkapan Jawa Berleksikon Hewan}

(1) Aja perek kebo gupak, artinya jangan berteman dan bergaul dengan orang jahat karena pasti nantinya akan ikut-ikutan/terbawa-bawa. Maknanya, artinya berkumpul dengan orang jahat akan terpengaruh jahat. (jawa, artinya cedak karo 
uwong ala bakal katut ala). (2) Ana lapang ana walang, ana banyu ana iwak. Artinya, artinya dimana pun berada pasti akan tersedia rezeki buat kita. (3) Asu belang kalung banda. Peribahasa tersebut secara harfiah berarti anjing belang berkalung uang. Secara lebih jauh peribahasaini inginmenggambarkan keadaan orang yang secara visual buruk atau secara social tidak mempunyai peringkat yang tinggi (tidak berpangkat atau berjabatan) namun ia memiliki kekayaan yang berlimpah. Asu (anjing) dalam masyarakat jawa termasuk binatang yang sering digunakan sebagai bahan misuh (memaki). Dengan demikian, ia memiliki derajat yang buruk sekalipun dalam praktik anjing memang banyak digunakan untuk membantu orang terutama dalam soal keamanan. Bukan hanya itu. Asu belang (anjing bercorak/ berbulu belang) dalam masyarakat jawa masa lalu termasuk kategori anjing yang bernilai paling rendah. (3) Asu gede menang kerahe. Maknanya orang yang punya kedudukan/ pangkat/ jabatan yang tinggi pasti lebih tinggi kekuasaannya. (jawa, artinya uwong kang duwur pangkate mesti gede panguasane). (4) Asu munggah ning papahan, artinya laki-laki yang menikah dengan janda kakaknya (baik kakaknya masih hidup atau sudah meninggal).

Fungsi peribahasa itu bukan hanya mempertegas tetapi juga memperlembut pengucapan. Fungsi Bahasa. Bahasa Banyumas sebagai media peribahasa memfasilitasinya, baik dari sisi potensi keunikan bahasanya (bahasa ngapak) maupun dari sisi kedalaman jangkauan pesan, makna, dan mampu merangkum berbagai motivasi pemakainya.Motivasi pemakaian pearibahasa banyumas intinya adalah menunjukkan kearifan lokal (cara-cara untuk mengatasi persoalan kehidupan mereka dengan cara yang baik dan benar menurut tradisi setempat) mereka melalui fasilitas bahasa Banyumas yang unik.

\section{Fungsi Etika}

(a) Nandur pari thukule beras,nandur kembang mawar thukule eri (etika)

Artinya : Barang siapa menanam kebaikan akan menuai kebaikan, dan barang siapa menanam keburukan akan menuai keburukan pula.(b) Ora Ana Sumur Marani Timba. Secara bahasa diartikan sebagai "tidak ada sumur yang mendekati timba", karena memang di manapun selalu timba yang mendekati sumur ketika orang hendak mengambil air. Maksud dari peribahasa ini adalah bahwa manusia selalu membutuhkan pertolongan orang lain. Namun, orang yang membutuhkan pertolongan itu, tidak seharusnya meminta orang yang dimintai bantuan untuk mendekat kepadanya.(c) Mopoki taisejumbleng. Secara bahasa artinya "melumurkan kotoran (faces) sebanyak yang ada di jamban". Maksudnya peribahasa ini biasa digunakan oleh orang tua ketika dia mengumpat kepada anaknya yang seringkali berbuat hal-hal yang memalukan keluarga.(d) Puasa 
godhong pring. Arti dalam bahasa Jawa yaitu esuk-esuk nyanding piring, dalam bahasa Indonesia artinya pagi-pagi sudah menghadap makanan atau dalam kata lain diartikan sebagai sarapan. Peribahasa ini menjelaskan tentang orang yang sudah berniat puasa akan tetapi pagi-pagi sudah sarapan. (e) Balik gondok, memiliki makna meminta kembali sesuatu yang telah diberikan kepada orang lain. Peribahasa ini sering digunakan untuk mengatai seseorang yang kikir karena meminta kembali pemberianya dengan kata lain tidak ikhlas.

Fungsi etika peribahasa masih mempertahankan eksistensi pemakaian peribahasa Banyumas yang mengandung kearifan lokal, karena adanya tuntutan faktor etika (tuntutan kesantunan berbahasa).Pemakaian peribahasa Banyumas dihadirkan dengan harapan bisa memenuhi faktor etika komunikasi. Misalnya penggunaan peribahasa yang digunakan sesuai dengan faktor etika adalah njunjung dhuwur mendem jero yang bermakna "Seseorang agar selalu berbakti juga menjunjung tinggi harkat martabat baik keluarga, agama, maupunnegara dan menutupi aibnya

\section{Fungsi Sosial}

Nilai moral socialyaitu nilai yang berkenaan hubungan dengan masyarakat, suka memperhatikan kepentingan umum (Nugiyantoro, 2002:321). Dalam peribahasa dapat dideskripsikan sebagai berikut. (a) Kaya ngaproki tai meng rai. Anak yang bikin malu orang tua maksudnya si anak melakukan kesalahan yang sangat fatal pada orang tuanya. Oleh karena itu, peribahasa ini mengisyaratkan bahwa anak sejatinya menjaga martabat dan kehormatan orang tua sehingga dalam kehidupannya dapat membawa kebaikan baginya ataupun oraang tuanya. (b) Gupak pulute ora mangan nangkane. Peribahasa Banyumas ini memiliki arti kesialan yang mana tidak menikmati hasilnya tetapi menerima risiko jeleknya. Hasil jerih payahnya dinikmati oleh orang lain. (c) Bocah Polah Wong Tuwa Kepradah. Artinya ketika anak bertingkah laku macam-macam dan membuat masalah, orangtua akan terlibat (tersandung) dalam masalah tersebut. Ibaratnya, orangtua akan tersandung-sandung oleh masalah yang dibuat anaknya. Reputasi orangtua di dalam masyarakat juga akan ikut tercemar ketika anak-anaknya bertingkah laku buruk dan menyebabkan masalah dalam masyarakat. (d) Ngono ya ngono, ning aja ngono. Peribahasa ini memiliki makna bahwa begitu ya begitu, tapi jangan terlalu begitu.Maksudnya adalah jangan terlalu berlebihan ketika kita bertindak atau melakukan sesuatu.(e) Anget-anget tembelek ayam, artinya kemauan sesaat. Peribahasa ini sering digunakan untuk mengatai orang yang ingin berubah namun kemauannya hanya sesaat dan setelah itu kembali seperti sedia kala.

Eksistensi pemakaian peribahasa Banyumas yang mengandung kearifan lokal, karena adanya tuntutan faktor sosial. Oleh karena itu, pemakaian peribahasa 
Banyumas menjadi penting bagi masyarakat di Kabupaten Banyumas untuk menjaga suasana masyarakat yang mengedepankan kerukunan, kekompakan, gotong-royong, saling menghormati. Oleh karena mereka masih memiliki nilai-nilai kearifan lokal yang didukung oleh bahasa yang indah, menghindari suasana konfrontasi langsung (sehingga bahasanya dikiaskan/ dimetaforiskan/ dibiaskan/ makna konotatif/perlambang), keperluan tradisi (saat tertentu bahasa Banyumas diekspresikan tidak sama dengan bahasa sehari-hari) menuntut suasana yang membuat mereka berkelompok dalam waktu yang tertentu bahkan berlama-lama, sehingga salah satu pengikatnya adalah pemakaian bahasa Banyumas yang menarik, menyenangkan dan bernuansa indah itu (peribahasa Jawa). Seperti diungkapkan oleh perangkat desa usung-usung lumbung yang bermakna "bekerja sama membangun desa". Dapat dilihat juga dalam masyarakat Banyumas apabila ada warga yang sedang membangun atau merenovasi rumah secara serta merta tetangga atau warga sekitar akan membantu bersama-sama membangun rumah tersebut.

\section{Fungsi Ekonomi}

(a) Sing dodol nganti bokonge ora keton, artinya penjual yang dagangannya laris dan sampe antrian pembelinya panjang. (b) Ana Dina Ana $\boldsymbol{U} \boldsymbol{p a}$,memiliki makna tentang kehidupan yang harus terus optimis, tidak boleh putus harapan. Ungkapan ini memberikan nasihat kepada kita bahwa selama ada hari atau waktu, maka ada rezeki bagi setiap orang yang diberikan oleh Tuhan. (c) Gelem Obah Mesti Mamah, memiliki arti yang hampir mirip dengan ora ongkek ora nyekek, tapi makna dari gelem obah mesti mamah adalah asal mau berusaha pasti ada jalan. Ungkapan ini menjadi penyemangat bagi manusia untuk terus berusaha dalam menjalani kehidupan. (d) Ketiban duren diaweh semangka (sudah mendapat keuntungan, mendapat keuntungan lain lagi). Peribahasa ini sering digunakan ketika ada seseorang mendapat keuntungan yang tidak sedikit namun orang itu mendapat keberuntungan lagi (begja).

Eksistensi pemakaian peribahasa Jawa yang mengandung kearifan lokal, karena adanya tuntutan faktor ekonomi (adanya tuntutan nafkah keluarga dengan memaksimalkan kemampuan berbahasa Banyumas untuk melayani khalayak yang membutuhkan).Adanya individu atau kelompok orang dengan motivasi yang terkait faktor ekonomi ini, di Kabupaten Banyumasdikenal dengan perwatakan optimis dan tegas. Hal itu seperti diutarakan oleh salah satu pesan orang tua terhadap anaknya bahwa ana dina, ana upa yang bermakna "Ada hari, ada nasi". Pesan yang terkandung dalam peribahasa Banyumas tersebut adalah selama seseorang mau bekerja dengan tekun setiap hari maka ia akan tetap dapat memenuhi kebutuhan keluarganya. 


\section{Fungsi Politik}

Fungsi Politik. Eksistensi pemakaian peribahasa Banyumas yang mengandung kearifan lokal karena adanya tuntutan faktor politik yang didukung oleh faktor budaya, bahasa, estetik, etik, sosial (tuntutan kesantunan berbahasa untuk menjaga suasana dingin, agar tercipta kerukunan, kekompakan, gotongroyong, saling menjaga rasa hormat). Betapa pentingnya pemakaian bahasa yang bersifat metaforis seperti peribahasa Banyumas karena dapat menghaluskan budi pekerti dan membangun kerja sama dan jauh dari emosi dalam berbahasa. Seperti hal dalam pencalonan pejabat pemerintahan selalu berkampanye untuk beberapa program kerja yang akan dilaksanakan. Namun, seseorang berkata aja gedhen odolyang berarti "Jika mempunyai program, disesuaikan dengan kemampuan". Baik kemampuan diri sendiri maupun kemampuan daerah dan sumber daya manusia yang dipimpinnya. Setiap calon pemimpin biasanya berjanji melebihi batas kemampuannya sehingga segala program kerja yang dikampanyekan tidak dapat terlaksana.Oleh sebab itu, peribahasa tersebut terucap oleh seseorang dengan tujuan mengingatkan calon pemimpin untuk selalu mengukur kemampuannya saat membuat program kerjanya dan tidak merugikan kehidupan berbangsa dan bernegara.

\section{Fungsi Geografis}

Eksistensi pemakaian peribahasa Jawa yang mengandung kearifan lokal karena adanya faktor geografis (tempat, ekologi). Ketika faktor budaya, bahasa, estetik, etik, sosial menjadi pertimbangan penting pada saat seorang guru di Banyumas berpesan pada muridnya teka ngimbuih, lunga ngelongi, bahwa "selalu memberikan manfaat kepada orang lain”. Seorang guru tersebut mengekspresikan peribahasa Banyumas sebagai penegas karena pilihan peribahasa Banyumas untuk siswa atau pendengar yang mayoritas berasal dari Banyumas. Hasil penelitian menunjukkan bahwa ketika peribahasa Banyumas itu digunakan sekiranya pendengar atau yang mendengarkan tidak sesuai konteks dengan bahasa Banyumas berdiksi tinggi, maka peribahasa dapat diselaraskan dengan lingkungan sekitar. 


\section{KESIMPULAN}

Hasil penelitian ini dapat disimpulkan sebagai berikut: (1) Fungsi budaya menghasilkan naluri positif kebanyumasan; (2) Faktor bahasa menghasilkan leksikon tumbuhan dan hewan; (3) Faktor etika peribahasa Banyumas dihadirkan dengan harapan bisa memenuhi etika komunikasi ; (4) Faktor sosial pemakaian peribahasa Banyumas menjadi penting bagi masyarakat di Kabupaten Banyumas untuk menjaga suasana masyarakat yang mengedepankan kerukunan, kekompakan, gotong-royong, saling menghormati; (5) Fungsi ekonomiperibahasa Banyumaskarena adanya individu atau kelompok orang dengan motivasi yang terkait faktor ekonomi; (6) Fungsi politikadanya tuntutan faktor politik yang didukung oleh faktor budaya, bahasa, estetik, etik, sosial (tuntutan kesantunan berbahasa untuk menjaga suasana dingin, agar tercipta kerukunan, kekompakan, gotong-royong, saling menjaga rasa hormat; dan (7) fungsi geografis dapat mencirikan ke-Banyumasan seseorang. 


\section{DAFTAR PUSTAKA}

Ahimsa-Putra, H. S. 2007.Patron \& Klien di Sulawesi Selatan: SebuahKajian FungsionalStruktural. Kepel Press. Yogyakarta.

Koentjaraningrat. 2009. Kebudayaan Jawa. Balai Pustaka. Jakarta.

Kridalaksana, Harimurti. 2001 (Edisi Ketiga).Kamus Linguistik. PT Gramedia, Pustaka Utama. Jakarta.

Moleong, Lexy J. 1993. Metode Penelitian Kualitatif. Remaja Rosdakarya. Bandung.

Nurgiyantoro, Burhan. 2002. Teori Pengkajian Fiksi. Gadjah Mada University Press. Yogyakarta.

Spradley, James P. 1997. Metode Etnografi. Tiara Wacana Yogya. Yogyakarta.

Subroto, Edi. 1992. Pengantar Metoda Penelitian Linguistik Struktural. Sebelas Maret University Press, Surakarta

Sutopo. 2006. Metodologi Penelitian Kualitatif. UNS. Surakarta 